\title{
Construction and Application of MOOC-based College English Micro Lesson System
}

\author{
https://doi.org/10.3991/ijet.v12i02.6374 \\ Zhang Erwen \\ Anhui Polytechnic University, Wuhu, China \\ zhangerwen $81 @ 163 . \mathrm{com}$ \\ Zhang Wenming \\ Anhui Polytechnic University, Wuhu, China \\ $13956183660 @ 163 . \mathrm{com}$
}

\begin{abstract}
- this paper aims to introduce the construction and application of MOOC-based micro lesson system in college English teaching, which, based on MOOC concept, micro lesson pattern and multimedia cognition theory, can greatly enrich the teaching contents, enlarge the multiple interaction, improve the learning efficiency and realize the ubiquitous teaching for college English students. This paper shows that the application of MOOC-based micro lesson system in college English teaching can bring about profound changes to the traditional college English teaching, which can serve as a successful example to be followed in the current college English teaching reform in China.
\end{abstract}

Keywords-MOOC, Micro Lesson, Multimedia cognition theory, College

English teaching.

\section{Introduction}

As was proposed in National Medium and Long-term Educational Reform and Development Plan (2010-2020), the acceleration of educational informatization process needs to strengthen the application of educational resources, promote the popularization of good educational resources, enhance the construction of web teaching resource system, explore the web learning curriculum, and innovate the web teaching mode. Concerning the teaching reform of college English, MOOC and micro lesson, with their multiple advantages in video and web utilization, have brought about profound influences in the form of college English teaching and learning. They can help improve the integrated English ability of students and transform the traditional college English teaching into the web teaching, so as to realize the combination of teaching software and classroom instruction.[1] 
This paper, in view of the above-mentioned current trend, firstly gives a brief introduction of MOOC, micro lesson, multimedia cognition theory and their revelation to college English teaching, then analyzes in details the construction of college English micro lesson teaching mode, which is followed by an elaboration on the design and realization of college English micro-lesson teaching system. At the end of this paper, the application of college English micro-lesson teaching system and its feedbacks are demonstrated in accordance to the teaching reforms taken in our university.

\section{Inspiration of MOOC and Micro Lesson to College English Teaching}

\subsection{MOOC and the design of college English micro lesson teaching system}

The year of 2012 saw the entrance of the Massive Open Online Course (MOOC) into the popular rhetoric surrounding higher education reform, [2] when such MOOCs as Coursera and edX rose to prominence and attracted the attention of many world famous universities, with whose participation, MOOC became more and more popular.

The core of MOOC is curriculum, which is generally designed with fewer teaching weeks and hours. The teaching content of MOOC is mainly in the format of short video clip, which is pre-produced and free to watch or download. The course exercise is usually embedded in the video clip and designed for automatic marking or mutual comments among peers. The discussion concerning the course is carried out by forum, learning community or other media for social interaction.[3] Therefore, MOOC features an online curriculum development mode, which starts as a resources release and learning management system and becomes a new curriculum development mode by combining the old learning management system with more open network resources. [4]

Inspired by MOOC's concept, the traditional college English teaching, which mainly takes place in the form of classroom teaching and focuses largely on students' acquisition of language points, can establish an online micro lesson teaching system, which should be designed not only as a website for resource publishing and downloading, but also as a teaching platform which provides teachers and students with exclusive discussion zone, free privilege and flexible ways in resource sharing, and integrates resource sharing with community discussion.[5]

\subsection{Development and definition of micro lesson}

At abroad, the concept of "Micro Lesson" was first proposed in 2008 by David Penrose, the advanced teaching designer and online service manager of University College of San Juan, New Mexico.[6] He compressed the teaching video clips that last for hours into those of a few minutes, so that students can acquire knowledge very quickly by online or portable study. 
At home, Prof. Zhang Yi-chun of Nanjing Normal University holds that micro lesson is a kind of short but complete teaching activity which focuses on one language point or one teaching procedure, and presents itself in the form of streaming media so that learners can achieve the optimal learning effect by autonomous study. Prof. Jiao Jian-li of South China Normal University holds that micro lesson is learning or teaching-oriented online teaching video which aims to illustrate one language point and presents itself in the form of short, concise online video clips.[7]

\subsection{Necessity of college English micro lesson teaching}

The study of micro lesson, either theoretical or practical, has already infiltrated into every aspect of education. However, after investigation, it is shown that micro lesson is at present mainly applied in middle school or primary school, while in colleges and universities, micro lesson is still unfrequented; the study of micro lesson weighs much more on theoretical research than that in actual application; the micro lesson teaching is seldom carried out in the concrete courses, particularly in English courses. But, compared with the traditional college English teaching mode, it is evident that college English micro lesson teaching has its advantages in the following aspects:

Enrichment of classroom teaching contents: College English micro lesson teaching can break the limit in traditional college English classroom teaching that teacher is the only information resource for the students. In micro lesson teaching, students can watch the video contents delicately designed by teacher, practice the after-class exercises, learn the latest materials and listen to the explanation of teacher on the teaching focal points.

Enlargement of interactive contents: Through college English micro lesson learning, students can interact with teachers and peers online before, during and after class about the learning contents and difficult points involved. In this way, students' ability of speaking and communication is practiced.

Improvement of learning efficiency: The video clips in micro lesson are the core contents in teaching, which, after processing, have omitted a lot of redundant information. Under the dual stimuli of visual and auditory senses, learners can finish the acquisition of knowledge in a short time, thus, the learning efficiency is improved.

Ubiquity of "classroom teaching": As long as the teacher finishes the preparation of micro lesson, students will be able to conduct online learning with no limits of place or time. They can watch the video and speak aloud to improve their oral English at home, or have class during the weekend through the internet and conduct the autonomous learning according to their own learning progress.[8]

\section{Significance of Multimedia Cognition Theory to College English Learning}

The capacity of human's working memory is finite, and only in the way of scheme can more information be stored so as to greatly reduce the burden of working memory. The spatial and temporal synchrony of verbal and image information will 
form the connection between verbal and visual representation during the encoding of information, which is of great help in expanding the information extracting path and improving the learning efficiency of learners.[9] In 2001, the American scholar Mayer put forward the multimedia cognition theory, and proposed the model of multimedia cognition theory, which holds that human's information processing system can be divided into two independent panels, i.e. aural panel and visual panel, with the cooperation of which, materials presented to the learners are processed into a systematic structure, and further combined with the previous knowledge of learners. In the process, the utilization of dual panels can profoundly facilitate the learning effects.

Since English learning has particular requirement on aural and visual situations, the content of college English micro lesson system is mainly presented in the form of video, which can make good use of the function of dual panels, and reduce the cognitive burden of learners during the learning process. Under the support of dual panels, new language points can assimilate into the previous acquired knowledge so that learners can construct the meaning of new knowledge and achieve the desired learning effects.[10]

\section{Construction of Colleage English Micro Lesson Teaching Mode}

In order to improve the effect of college English teaching, a college English micro lesson teaching mode should be constructed to realize the flipped classroom, which includes four stages, i.e. design \& production of micro video before class by teachers, micro video learning before class by learners, interaction between teachers and students in class, and online interaction between teachers and students after class.

\subsection{Collection and production of micro video}

To have a detailed and thorough design of micro video, firstly, teachers need to choose the topics, determine the teaching contents and generalize the key points. Secondly, they need to control the teaching time within 10 minutes so that the teaching video can concentrate more language points. Thirdly, they need to ensure the vividness and completeness of the teaching video, i.e. a proper, quick lead-in, a clear demonstration and a concise conclusion should be guaranteed.

Concerning the production of micro video, teachers need to choose the proper shooting and producing tools according to the actual situation. Firstly, a digital camera might be used and the video be processed by non-linear editing. Secondly, such intelligent portable terminals as smart phones or pads might be used for shooting, this method features flexibility, users can shoot the key contents according to the actual cases. Thirdly, various screen recorder software can be used to record the screen contents and voices inside or outside the computer. This method applies to multi-video clips, which ensures the fidelity of pictures and voices recorded. One of the commonly used software is Camtasia Studio. Fourthly, the writing pad and interactive white board might be applied to the process of recording videos. This method applies to 
manual operation of multi-videos, which can realize the live record and reproduce the teaching progress.

Besides, according to the actual teaching requirements, teachers can search on the web for some short, concise video clips, such as some popular video clips in Moocs, or some video clips concerning the daily communications between native English speakers. In this way, students can feel the western culture, correct manner of communication and authentic linguistic expressions, which is of great help to the improvement of their oral English, listening comprehension and speaking tones, etc..

\subsection{Release of video before class}

After finishing the production of micro video, teachers can use college English micro lesson teaching system to assist classroom teaching. Before the classroom teaching, teachers can upload the video to the server, where the streaming media converter converts the video into the streaming format which improves the transmission fluency of the video in the web. Then, on the bottom of the video, teachers can add some text, exercise or test. Only at this moment can students' learning be declared to commence. Students can log on into college English micro lesson teaching system by wired computer or portable terminals, and learn the video uploaded by the teacher. During the process of learning, students can watch the video repeatedly, imitate the pronunciation of difficult words or sentences, refer to the translated scripts when they find some expressions difficult to understand, and express their opinions or conduct an online communication with the teacher or other students when they meet some questions concerning the learning video.

\subsection{Classroom teaching}

During the classroom teaching, teacher is no more the traditional instructor of language points, students are neither the passive receivers of knowledge or information. When reviewing the language points in the video, teacher can supplement some blackboard-writing or electronic documents to satisfy various learning needs of students. Then, the most frequently asked questions about the learning contents on the web will be answered by the teacher. After that, sufficient time will be reserved for interaction, when students are divided into groups to discuss or practice the pronunciation, translation, grammar or cultural phenomenon learnt from the video. In this way, the learning of concrete language points will be enhanced and the internalization of knowledge will be realized. During this process, teacher needs to strengthen the organization and instruction of students' group discussion and enlarge their cognitive structure step by step, so as to improve students' ability of language transfer.

\subsection{After-class Introspection and Interaction}

Introspection, as an important means of self-improvement, can be conducted by students at a deeper level after they've fully absorbed what the teacher had supplemented in class. College English micro lesson teaching system needs to provide a tool 
for introspection and interaction of teacher and students to realize synchronous or asynchronous communication.[11] After introspection, students can go on discussing what they have learnt in class on the internet, expressing their opinions and interacting with their teachers. Besides, students can upload to the internet the relevant video clips, which, after approved by their teacher, will be watched by other students for further discussion. Nowadays, it is an undisputable fact that SNS (Social Networking Services) have been widely used in communication among college students, who, therefore, can share the micro-lesson video clips in various SNS so as to be watched, learnt and discussed in a broader way.[12]

\section{Design and Realization of College English Micro-Lesson Teaching System}

\subsection{Structural construct of the system}

The college English micro-lesson teaching system takes PHP + MySql + Apache as its technical construct, and the whole platform uses Apache as its Web server. As is well-known, Apache is the most popular and most frequently used Web server software in the world, which, with excellent performance in compatibility and safety, can be run on almost all computer platforms that are widely used. Concerning data base, MySQL database is applied, which, as a small-scale database management system, features little cubage, high speed, low cost and open resource code.[13] The college English micro-lesson teaching system develops many Ajax-based modules so as to provide an environment for live interaction among teacher and students via the platform, and as the synchronization between the page and the data in the database is realized, there will be no long waiting for the page to be refreshed.

\subsection{Design of database}

As the micro-lesson teaching system features learners' participation, learners and videos are the two cores for the construct of system, when they both shall be taken as a link to connect the learning contents. Therefore, the design of database shall take learners' information table and video information table as the most important parts of database, which shall be detailed and comprehensive enough to prop up the whole structure of database. The two tables are connected through learners' name, so that the learners' information and video information can be mutually transferrable. Besides, some affiliating tables such as comments table, collection table, learners' friends table, log-on table and watching table are also properly designed.

\subsection{Realization of functional modules}

Video play: in the video play interface, learners can use the simulated situations created by the video contents and improve their comprehensive abilities in listening, 
speaking, reading, writing and interpreting through multi-channels. Besides, multiple interactive activities can be realized between teacher and students. Firstly, learners can make their comments on the video conveniently by clicking the button of "like" or "dislike"; secondly, learners can click the button of "store" to collect the video into their learning data base for future review; thirdly, learners can click the button of "share" to share the video in their QQ space, micro blog, etc., so that the video can not only be stored in their social media but also be viewed by others using the same social media; fourthly, learners can make their detailed comments on the video and carry out a real-time interaction with the video uploader and other commenters; fifthly, when learners watch a video clip, a list of video clips containing the similar content will appear automatically on the right side of the screen, ready for learners to check.

Recommendation of tailored videos: To satisfy learners' individualized needs for video learning and save their time in searching for needed videos, the system provides the function of automatic video recommendation. After learners have registered in and watched some videos, the system will store their information into the data base and set up a tailored homepage where some videos that learners have not yet watched but might be interested in are recommended. Besides, the system will recommend to learners some popular videos where learners can appreciate western culture, literature critics and those most learners are interested in. Similarly, during the learning process of college English, learners can easily see the mistakes commonly made by others learners so that they might avoid them in their own study.

Socialized learning process: During the learning process, learners can add each other to their friend list through the interface of friends' management, so that they can communicate with each other conveniently and enter each other's personal space for browsing and watching the uploaded videos. Besides, learners can recommend their friends to others so as to enlarge their friends' circle, through which, learners can conduct their English learning mutually so as to improve their English learning as a whole. Similarly, learners from the same class can group themselves according to their own will so as to discuss their learning contents, evaluate themselves, inspire their learning motivation and thus improve their English level.

Online communication between teacher and students: The college English micro-lesson teaching system establishes in particular a platform for communication between teacher and students, i.e. "many-to-one" live chatroom, where teacher and students can exchange their ideas about various questions students meet in their English study. At the teacher's end, questions asked by students will be promptly shown and answered either by the teacher or other students, which will improve the interactivity and creativity of English learning for students and enhance their ability of English performance.

Tracing of learning behaviors: teacher can trace the learning behaviors of students to acquire their detailed learning information. Firstly, teacher can check the login accounts and logging time of students; secondly, teacher can check the relevant information of the uploading videos, such as the uploader, the uploading time and the uploading contents; thirdly, teacher can check the relevant information of video watching, such as video watchers, watching time and video contents; fourthly, teacher 
can browse all the comments on the video made by all the learners. By all the means mentioned above, teacher can monitor the overall or specific learning information of the students so as to work out an effective way of college English learning.

Autonomous learning: as pointed out by famous linguist Andrew D. Cohen, "the success of language learning depends largely on the learners themselves, i.e. their ability of utilizing all kinds of learning opportunities.'[14] Teacher needs to optimize and collect promptly all the learning resources available on the internet, and according to the patterns of English learning, categorizes them into the sequence of word, grammar, reading and writing or that of listening, speaking, reading and writing, so as to help students to improve their efficiency of autonomous English learning. Meanwhile, students can refer to their own strength and weakness in English learning, and work out an individualized plan for training their listening skills, communication strategies, writing techniques, reading comprehension, testing methods or translation skills.[15] In this way, students' knowledge will be broadened and their interests in English learning will be further aroused as a whole. And for those who have a better basis for English learning, a chance will be provided for them to further strengthen their Knowledge in English and ability in English application.

\section{$6 \quad$ Application of College English Micro-Lesson Teaching System and its Feedbacks}

With the successful construction of college English micro-lesson teaching system, we started to apply it in college English teaching in our university in 2014, and after 3 years of practice, remarkable changes have taken place in various aspects in college English teaching. Feedbacks on the reform have also been collected through questionnaires distributed among teachers and students. A detailed analysis of both the changes and feedbacks will be made in the following.

\subsection{Remarkable changes}

Flipped English class: in the traditional college English teaching, classroom is the main place where knowledge teaching and learning take place. Due to the overlarge class scale and the limited teaching hours, few time can be left for students to practice what they've just learnt, which leads directly to the unfavorable learning results.

However, with the application of college English micro-lesson teaching system, the impartment of knowledge is carried out before class, when teacher designs and upload the teaching video clips, and students watch them and the attached training assignments. While in class, time will be spent mainly on the internalization of knowledge, i.e. quick assessment, problem solving and learning feedbacks. In this way, the college English class is flipped so as to provide sufficient time for students to practice their language skills.

Formative evaluation: in the traditional college English class, the summative evaluation is applied by grading students in the final examination. Now with the application of college English micro-lesson teaching system, the formative evaluation 
can be realized when teacher can monitor the whole learning progress of the students by collecting all the relevant learning behaviors of students in the system, i.e. their log-in time, their watching contents, questions they've asked and their communication with others. In this way, teacher can form a thorough evaluation on not only the cognitive ability of students but also their emotions, demands and potential for tailored further development. Students are granted a chance for continuous improvement and perfection, which is of great help to their health both cognitively and psychologically.

Better input effect: compared with the traditional college English teaching when the language input is realized mainly in class by teacher, the current college English teaching mode can complete the language input in a more effective way. With the application of college English micro-lesson teaching system, students can acquire the language input before class by watching the video clips in the system. Since the video clips are of dual panel and available for repeated watching, students can enjoy a more interesting and less anxious experience in the process of language input.

Output-driven teaching aims: as was discussed above, in the traditional college English class, teacher spare no efforts in imparting English knowledge in class with few time left for students to practice, which will definitely cause a unguaranteed learning outcome. However, with the aid of college English micro-lesson teaching system, teacher can weigh a lot more on the learning output than before. Firstly, the video watching time is not only meant for students to take the input, but also as a way for them to practice their speaking and writing when they are communication with others in the system; secondly, considering English is a foreign language in the mainland of China, which means students can hardly find opportunities to practice their English out of English classroom, the system is exactly a perfect space for them to use English; thirdly, since most of the input job is done before class, most of the class time will be spent in strengthening their output.

\subsection{Favorable feedbacks}

To examine whether all the above-mentioned changes are welcomed by teachers and students, questionnaires concerning the degree of satisfaction are designed and distributed among all the teachers and students involved in the reform of college English teaching in our university, the data collected and analyzed thereafter show that most of the teachers and students are in strong support of the application of college English micro-lesson teaching system.

Teachers hold that they are now enjoying more freedom in designing their teaching contents and feeling more sense of success when they can spend more time in monitoring students' practice of English instead of teaching the basis language skills, while students are also happy to enjoy a more flexible and less anxious way to learn new knowledge, and more importantly, to find more fun and chances to practice their English.

However, the survey also reveals some challenges for both teachers and students. Teachers are reported to spend much more time in finding or even designing different teaching video clips for students, which reminds us that a closer relation of cooperation among college English teachers will be called for. Some students confess that 
sometimes they are not so well-disciplined in the before-class learning that they feel dragged behind in the discussion in class, which suggests that teachers should get more involved in the on-line communication with students and a stricter monitoring of teachers should be conducted in the future.

\section{Conclusion}

To college English learners, the vivid teaching video clips are far more intriguing than those traditional electronic texts and pictures, therefore, the learning interest and motivation of students can be better awoken.[16] The college English micro-lesson teaching system constructed above, based on the concept of MOOC, is a interactive teaching platform, where a more vivid, real and effective learning environment is provided for students to acquire the language ability through multi-interaction. Meanwhile, both teachers and students can share the videos in SNS, which breaks through the limits on the time and space meant for communication among them, and involves more students in the interaction and communication to a larger degree. To conclude, the construction and application of college English micro-lesson teaching system follow the current trend for video learning on the internet, which, by utilizing the vividness of video teaching resources, will definitely bring about profound changes in college English teaching and learning.

\section{$8 \quad$ References}

[1] X. Z. Si and H. Y. Zhao, "College English Course Design under the Teaching Mode of Constructivism”, Computer-Assisted Foreign Language Education, vol. 36, pp.70-74, 2013.

[2] A. Koutroloulus, "What Tweets Tell us About MOOC Participation", International Journal of Emerging Technologies in Learning, vol. 9, pp. 8-21, 2014. https://doi.org/10.3991/ ijet.v9i1.3316

[3] X. Zhang, "Revelation and Re-thinking of MOOC-based on-line Teaching Mode", Journal of Jiangsu University of Broadcasting and Television, vol. 26, pp. 5-10, 2013.

[4] Z. H. Ji, "Application and Empirical Investigation of New MOOC Teaching System in Computer Application Course", International Journal of Emerging Technologies in Learning, vol. 11, pp. 62-67, 2016. https://doi.org/10.3991/ijet.v11i05.5696

[5] Y. Zhou, Y. Z. Li and Y. D. Xu, "Design of MOOC-based Micro Lesson Website", Modern Information Technologies, vol. 37, pp. 114-118, 1995.

[6] Z. K. Guan, "On Micro-lesson Courses", Information Technologies Education of China, vol. 46, pp. 13-17, 2011

[7] T. S. Hu, M. Y. Huang and M. Li, "Three Stages in the Development of Micro Lesson in China and its Revelation", Journal of Distant Education, vol. 34, pp. 36-42, 2009.

[8] P. Liu and J. Qin, "Teacher's Guide, Supervision and Management on Web-based Autonomous Learning”, Computer-Assisted Foreign Language Education, vol. 30, pp. 63-67, 2007. 
[9] Y. L. Yang, T. Mi and S. Tang, "Manifestation of Multimedia Information in English Teaching from the Perspective of Multimedia-based Cognitive Theory", ComputerAssisted Foreign Language Education, vol. 32, pp. 42-46, 2009.

[10] K. K. He, "The Teaching Mode, Methods and Design based on Constructivism", Journal of Beijing Normal University, vol. 65, pp. 74-81, 1997.

[11] X. B. Cao, "Strategies on Cultivation of Information Technology Ability for Normal University's Students-A Video-based Case Study", China Educational Technology, vol. 51, pp. 104-108, 2013.

[12] Q. F. Wen, Study on English Learning Strategies, China: Shanxi Normal University Press, 2003.

[13] X. Ding, R. M. Huang and C. Yang, "Design and Realization of Web-based Teaching Platform”, Modern Information Technologies, vol. 52, pp. 104-109, 2010.

[14] A. Cohen, Language Learning: Insights for Learners, Teachers and Researchers, New York: Newbury House, 1990.

[15] X. Geng, "On College English On-line Autonomous Learning", Education Science, vol. 23, pp. 60-64, 2010.

[16] D. G. Zhao and J. Z. Jiang, "Construction Mode and Development Trend of Open-end Education Resources in High Education", Beijing University Education Critics, vol. 18, pp. 123-134, 2009.

\section{Authors}

Zhang Erwen is with Anhui Polytechnic University, Wuhu 241000 China (e-mail: 1748769412@qq.com).

Zhang Wenming is with Anhui Polytechnic University, Wuhu 241000 China (email: 13956183660@163.com).

This work was supported in part by Quality Course Project of College English of Anhui Province in 2013 and the teaching and research project of Anhui Polytechnic University under Grant 2014jyxm76. Article submitted 26 October 2016. Published as resubmitted by the authors 21 December 2016. 